\title{
LA LOTERÍA MEXICANA COMO HERRAMIENTA PARA FOMENTAR LA CULTURA VISUAL EN EL PROCESO DE DISEÑO EDITORIAL
}

The Mexican Lottery as a Tool to Promote Visual Culture in the Editorial Design Process

IRMA LUCÍA GUTIÉRREZ CRUZ

Universidad de Guadalajara, México

KEY WORDS

Visual culture

Visual-conceptual

representation

Lottery
ABSTRACT

The Mexican lottery is a classic Mexican game as an activity where the students of the Bachelor of Design in Graphic Communication at the University of Guadalajara develop and allow the reinforcement of knowledge of the editorial design process. Design a lottery with the theme, where the idea through the concept and management of the form: identifies the actors, with images of each of the processes, reinforcing the visual culture, build and share their visual references, is generated with the letters, a visual-conceptual representation of the actors and a learning that includes linguistic and verbal intelligence.
PALABRAS CLAVE

Cultura visual

Representación visualconceptual

Lotería

\section{RESUMEN}

La lotería mexicana juego clásico mexicano como actividad donde los estudiantes de la licenciatura en diseño para la comunicación gráfica de la Universidad de Guadalajara desarrollan y permite el refuerzo de conocimientos del proceso de diseño editorial. Diseñar una lotería con el tema, donde la idea a través del concepto y manejo de la forma: identifica a los actores, con imágenes de cada uno de los procesos, reforzando la cultura visual, construyen y comparten sus referentes visuales, se genera con las cartas, una representación visual-conceptual de los actores y un aprendizaje que incluye a la inteligencia lingüística y verbal. 
$\mathrm{E}$ l ser humano tiene la capacidad de retener nueva información e integrarla a varios aspectos de su vida, ya que al incluir imágenes, sonidos o interactuar con elementos a través de los sentidos, se estimula el factor sensorial de cada individuo, logrando así nuevos elementos que pueden llevar a transformar el conocimiento.

Diseñar es hacer de la disciplina y de sus especialización una herramienta donde los objetos visibles se vuelven una experiencia visual y de comunicación. Hay que considerar que el ser humano en la actualidad viaja en instantes por una carretera de miles de imágenes y que el cerebro con la capacidad absorbe y lo convierte, y que a través de los estímulos en este caso visuales se convierten en experiencias, mismas que pueden servir para momentos posteriores.

Para Joan Costa (2003) se logra con la imaginación producir un significado lo que resulta o produce de lo hecho por la mente, además de establecer la relación existente entre texto e imagen, donde uno complementa al otro, es decir lo que la imagen no puede decir se complementa con el texto.

La presente investigación parte de la importancia que tiene el desarrollo de las habilidades para crear y desarrollar gráficamente, desde el ambito estudiantil donde el alumno ha de proponer y crear elementos de comunicación; esta actividad surge de observar acciones creativas que le permite identificar términos desde el ámbito editorial cuyo objetivo es comprender y enteder este campo de acción, ya que los coceptos se han de identificar por el alumno con el fin de conocer y comprender el ámbito de la industria editorial, y de cómo el individuo almacena la información a largo plazo, donde la atención, percepción y la codificación estructura sus proceso cognitivo.

Por lo que Egge y Kauchak(2009) comentan que "la motivación es una fuerza que estimula, sostiene y dirige la conducta hacia una meta.....procesan información...persisten en tareas difíciles....tiene actitudes más positivas, surgen experiencias que generan valores."

El uso de una técnica creativa como elemento didáctico busca fomentar el sentido de la percepción de la imagen, con la identificación de conceptos relacionados con esa imagen. Por lo que con una actividad de gammificación basade en una mecánica de juego que ha de involucrar al individuo a la solución de problemas, el objetivo será realizar el juego y jugar, Borras (2015) en su texto menciona que los juegos ejercen un gran poder de disfrute en las personas y que com actividad lúdica dentro del aula le permite al permite al estudiante adquirir y/o reafirmar conocimientos, a través de estas acciones que han de convertirse en elementos didácticos para del proceso de enseñanza-aprendizaje.

Es a través de la representación visual que se estimula la captación de información, la codificación y el almacenamiento de elementos en la memoria a largo plazo, como menciona Joan Costa (2003) "la percepción es un acto visual que se ve, que puede llegar a ser una quimera visual".

El trabajar en el aula en actividades donde se involucra al individuo a crear y a dar uso de elementos que permitan construir su conocimiento, los motiva de tal manera que se puede lograr la cooperación y organización para obtener los objetivos planteados y el desarrollo de la actividad generadora del conocimiento y que tenga beneficio a todos los alumnos, Medina y Domínguez (2006).

Para Costa (2003) el lograr con la imaginación producir un significado lo que resulta de lo hecho por la mente, además de establecer la relación existente entre texto e imagen, donde uno complementa al otro, es decir lo que la imagen no puede decir se complementa con el texto.

Por lo que Eggen y Kauchak(2009) comentan que la motivación es una fuerza que estimula, sostiene y dirige la conducta hacia una meta.....procesan información...persisten en tareas difíciles....tiene actitudes más positivas, surgen experiencias que generan valores.

Desde el aspecto académico se busca fomentar el sentido de la percepción de la imagen para el diseño, donde a través de actividades lúdicas en el aula, permite al estudiante adquirir o reafirmar conocimientos, implementando acciones que han de convertirse en elementos didácticos para del proceso de enseñanza-aprendizaje.

Es a través de la representación visual que se estimula la captación de información, la codificación y el almacenamiento de elementos en la memoria a largo plazo, como menciona 
Costa (2003) la percepción es un acto visual que se ve, que puede llegar a ser una quimera visual.

Es por eso que se da uso de herramientas didácticas como un sistema de transmisión del mensaje de manera comprensible para el alumno, se definen a partir de los objetivos y contenidos marcados en un programa educativo, así como el uso de elementos que permitan la construcción del conocimiento, de tal manera que la cooperación y organización para obtener los objetivos planteados y el desarrollo de la actividad generadora del conocimiento tenga beneficio a todos los alumnos. (Medina y Domínguez, 2006).

Para la motivación en el alumno en cuanto a la adquisición del conocimiento se incorpora la actividad de la gamificación, acciones creadas a través de actividades creativas adaptadas a factores de enseñanza, donde el contenido que se ha de manejar lleve una carga teórica y relacionada con la temática en turno, así como el aspecto lúdico

Así mismo es la originalidad y la creatividad la que impulsa a la renovación del pensamiento, es donde se desarrolla un marco de la búsqueda de estrategias para integrar al alumno a la comprensión de aspectos teóricos y hacerlo partícipe de su propio conocimiento.

A partir de lo anterior, se hace una búsqueda dentro de los juegos tradicionales mexicanos que permita desarrollar acciones que se acople en la temática y aporte experiencia visual al estudiante. Por lo que el juego es una forma de aprendizaje creativo ya que estimula la imaginación y se crea un triángulo: imaginación, juego, creatividad, según dicen Alsina, Díaz, Giraldez e Ibarretxe(2013), ya que "creatividad y juego comparten una motivación intrínseca derivada el estímulo que despierta ocuparse por una actividad por el interés, placer, satisfacción y desafío del trabajo por sí mismo".

El objetivo de este ejercicio es desarrollar la capacidad creativa del alumno al manejar conceptos donde la imagen sea el contenido principal basado en el concepto inicial y a la tipografía como elemento auxiliar, para que les permita reafirmar el contenido temático.

Se seleccionó el juego "Lotería Mexicana" ya que se ha considerado como un juego clásico y que se ha identificado en la cultura mexicana, pues consta de la expresión de imágenes descriptivas derivadas de una cultura, y manifestada por imágenes relacionadas con la epoca a la que fue diseñada. Juego de mesa que aparece en la Guerra de Independencia y que culturalmente se tiene como un juego tradicional de mesa. La iconografía de la lotería se fue adaptando a personajes que representaban a la sociedad y las costumbres de los mexicanos.

La loteria como juego de mesa consta de diversos elementos: tablas, cartones en donde cada una consta de 16 imágenes/conteniendo signos visuales (ver imagen 1) y el nombre de la imagen con el uso de tipografia, más un mazo de cartas de todas las imágenes incluidas en los cartones.

Imagen 1. Aspecto visual de la lotería mexicana.

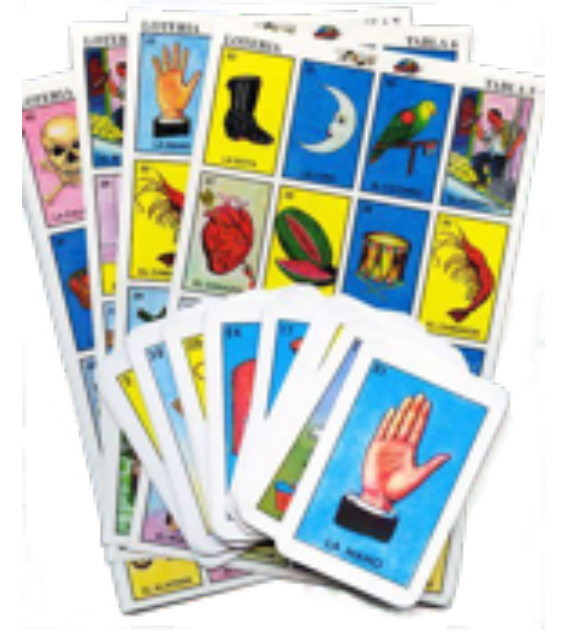

Este juego se desarrolla de la siguiente manera: cada jugador debe de tener una carta o cartón y usar marcador( en México se utiliza el grano de maíz o de frijol, corcholata o cualquier otro dulce o piedra) que le permitan identificar a la imagen que va apareciendo del mazo de cartas que se cantan o que se corre.

Antes del inicio de cada juego, los jugadores deben escoger sus cartones o tablas. Entonces, cada jugador debe contar con marcadores es decir con fichas para marcar la imagen que aparecerá al momento de cantar las cartas (es tradicional hacer la marca en la carta con frijol, corcholatas de refresco o granos de maíz). El mazo de 54 cartas se baraja y se comienza el juego cuando el "gritón" canta una carta al azar y anuncia el nombre de la carta o el acertijo que se relaciona con ésta. Si la imagen de la carta aparece en el juego del jugador, éste marca la 
imagen con el maíz, frijol o con lo que se cuente para hacer la marcación.

La manera de jugarse es la siguiente:

Se requiere de un gritón, la persona que anuncia las cartas que van saliendo. Esta persona controla las cartas de las imágenes que vienen en la carta, y las va sacando al azar sin ver de la baraja.

1. Se le da una carta a cada jugador, o bien 2 , depende de las reglas del juego.

El gritón saca una carta a la vez. Ejemplo: Grito inicial:

"Se va y se corre con la vieja del pozole!...... ¡La dama!

Algunos ejemplos de otras frases usadas para cantar el mazo de la lotería:

- El que a buen árbol se arrima buena sombra lo cobija...... el árbol.

- El sombrero de los reyes....la corona

- La muerte tilica y flaca......la muerte

2. Los jugadores colocan una ficha, frijolito o cualquier objeto pequeño que simule una ficha sobre cada imagen que corresponda a la imagen que anuncia el gritón.

Aquí el ganador será quien primero marque su carta completa, es decir que llene con frijol cada casillero que forma parte de su carta. Así el primero que la llene tendrá que gritar "lotería".

Variantes en el juego:

- Línea-el que consiga cubrir cuatro imágenes seguidas, ya sea de manera horizontal, vertical o diagonal puede gritar línea.

- Cuatro esquinas.- si completa las tarjetas que se encuentran en las cuatro esquinas de su carta, puede gritar cuatro esquinas.

- Centro.- El jugador hace centro cuando completa las 4 cartas que se encuentran en el centro de su carta.

- Horizontal.- El jugador hace cualquier línea horizontal y canta su línea.

\section{Desarrollo de la Actividad}

Ahora bien para insertar el juego de la lotería mexicana al contexto del aprendizaje se toma del programa de la materia de Diseño IV de la Licenciatura en Diseño para la Comunicación Gráfica en el Centro Universitario de Arte, Arquitectura y Diseño de la Universidad de Guadalajara, el contenido de la temática denominada proceso editorial. El objetivo de realizar este actividad ludo-gráfica es: reforzar los conocimientos adquiridos sobre la temática mencionada con anterioridad, donde a través de imágenes representativas y texto generará en el alumno el uso de éstas como cultura visual adquirida más un conocimiento teórico.

Para esta actividad es establecer en el alumno la importancia que tiene el proceso y sobretodo que él identifique dentro del rubro donde aparece el diseñador gráfico y cual es su papel el proceso editorial y además cómo esta temática se desarrolla al inicio del semestre, donde se parte del diseño de la actividad, la cual se les presenta a los alumnos en un documento donde se explica la actividad.

Imagen 2. Carátula de la actividad diseñada.

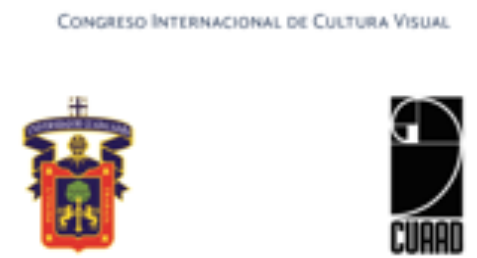

LA INDUSTRIA EDITORIAL.

DRa. lama Lucia Gutiérrez Cruz

TALLER DE DISEÑo IV

Lic. en Diseño para la Comunicación Grática Centro Universitario de Arte, Arquitectura y Diseño.

La actividad cuenta con acciones previas, una de ellas es: búsqueda de información, donde ellos trabajan en equipo y elaboran un collage para ir identificando la relación de diseño editorial y proceso editorial.

Imagen 3.- Resultado de la actividad previa.

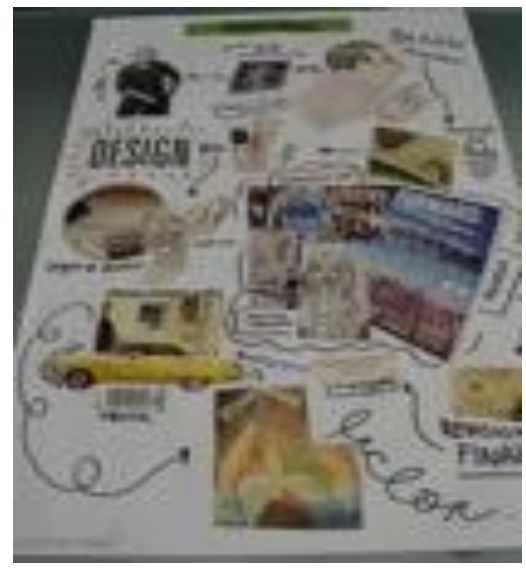


Se les hacen llegar documentos de lectura relacionados con el proceso editorial, donde ellos en trabajo de equipo definen cada personaje e identifican la actividad correspondiente y con material visual donde se le menciona y explica el proceso editorial.

A partir de esto, les pide a los alumnos que elaboren la Lotería del proceso editorial, basada en juego de la lotería mexicana antes mencionada.

Imagen 4.- Diagrama del proceso editorial con el que se basan para elaborar la lotería.

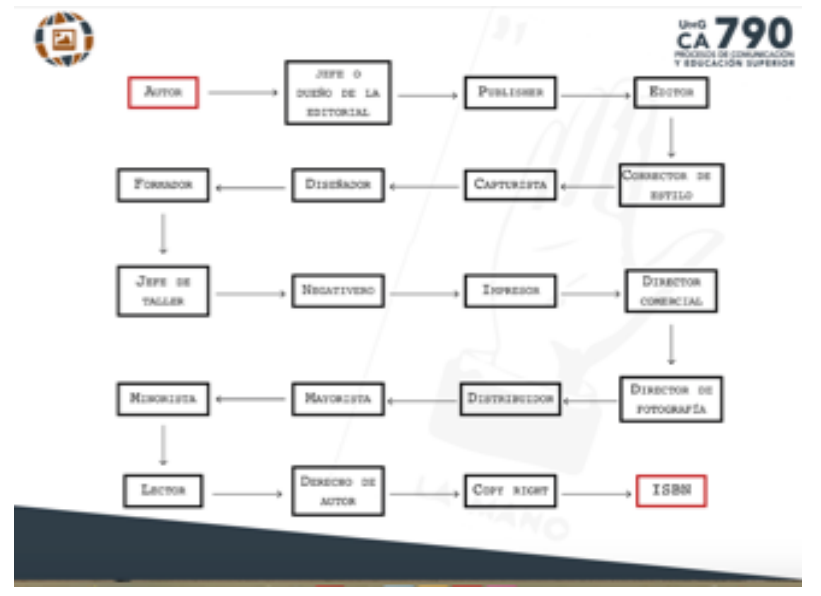

El objetivo principal es diseñar las cartas para poder jugar a la lotería, por lo que se le asigna a cada uno de los alumnos 3 personajes, cuya idea principal es él identifique cual es la actividad base que realiza y que lo defina con un aspecto visual. Una vez que ellos tienen a esos 3 personajes definidos con forma, color, tamaño y tipografía, lo reproducen 5 veces e intercambian con sus demás compañeros, y de esas 5 una carta se quedará para formar el mazo con el cual se cantará la lotería. La idea es que completen su carta, en este caso no contamos con 54 personajes como en la lotería tradicional, por lo que nuestra carta diseñada solo consta de 12 personajes diferentes en cada una de las cartas, en este caso fueron 11 cartas las que se elaboraron, por ser la cantidad de alumnos que forman el grupo en turno. La carta está montada sobre un cartón de que a su vez esta divido en 9 módulos, en cada uno se pegará una de las imágenes que fueron elaboradas y se intercambian entre ellos, es requisito que no se duplique una misma imagen en la carta. Ya armada la carta, se procede a realizar la actividad del juego.

Imagen 5.- Alumnos en el proceso de elaboración de su tabla o carta.

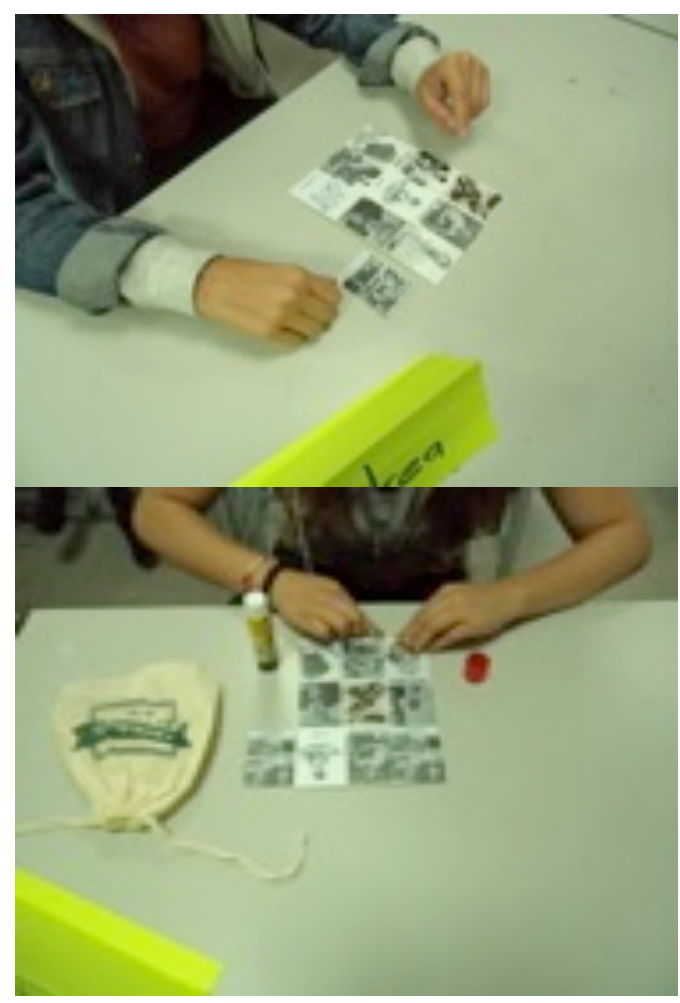

La lotería se puede jugar por diversión, pero para este proyecto ha se resultar un proceso de aprendizaje a través del desarrollo de la temática, se integran elementos de atención, competencia, y a su vez se logra el reforzar el conocimiento, pues se puede jugar tantas veces se quiera. para que haya interés en el juego, se ha desarrollado un sistema en donde al ganador en vez de "dinero" gana fichas de madera, que estas tienen grabado letras del abecedario al que más acumule se le otorga un premio al final del juego. 
Imagen 6.- Loteria elaborada por los alumnos de Diseño Editorial, calendario 2018B Y 2019 A de la Lic. en Diseño para la Comunicación Gráfica del Centro Universitario de Arte, Arquitectura y Diseño de la Universidad de Guadalajara

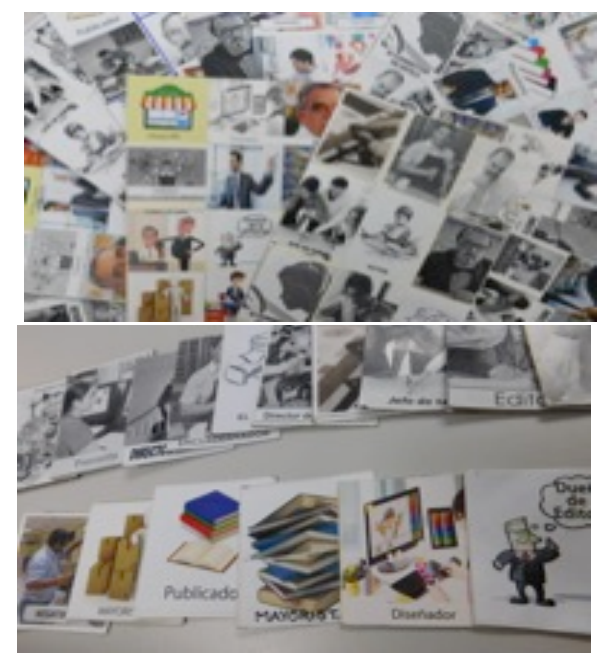

\section{Conclusiones}

Es para el diseñador importante compreder el desarrollo cognitivo relacionado con la imagen, ya que es a través de estas que se logra comunicar un mensaje, donde la expresión realizada creativamente con elementos visuales $\mathrm{y}$ donde la experiencia logra ampliar las vivencias significativas que como acciones educativas se trabajan dentro del aula.

El ser humano por naturaleza es activo, si estimulamos obtendremos reacciones por lo que se puede descubrir el hacer que se hace presente, mas si logramos que el alumno genere su propio conocimiento $\mathrm{y}$ al mismo tiempo reciba recompensas, se podrán motivar y despertar interés, así activará el cerebro y podremos darle un empuje al desarrollo del conocimiento en el alumno pasivo, inerte e incluso sin interés por lo que está pasando a su alrededor.

Al desarrollar la actividad mencionada en este comunicación podemos afirmar que se despierta en el alumno el interés a través del juego, en primer lugar se observa que se motivan al desarrollarla y poder elaborar ellos mismos su cartón y posteriormente el poder jugar, donde se centra la atención al querer ganar en la lotería; despierta sin duda su mayor interés, pues existe desde un inicio la duda de quién ganará e incluso se llegó a solicitar intercambiar las cartas entre ellos, sobre todo si la carta que ellos tienen no ha logrado ganar, mientras que observan que otra ha ganado más veces, claro que es un juego de azar y que no está predestinado.

La gamificación es por lo tanto un elemento visual-conceptual-metodológico vivencial-lúdica que aporta en el alumno el desarrollo de habilidades y sobre todo refuerza los conocimientos adquiridos basados en la experiencia lograda en el juego. Cuya mecánica importante es lograr recompensar al alumno por sus objetivos alcanzados, ya que si desmenuzamos cada proceso, puede generarse valores numéricos denominados calificación o incluso lograr experiencia visuales-creativas al generar competencia entre los alumnos, motivándolos a diseñar sus cartas de tal manera que la mejor realizada logre puntaje extra.

Imagen 7.- Alumnos jugando con la loteria elaborada sobre la temática del proceso editorial.

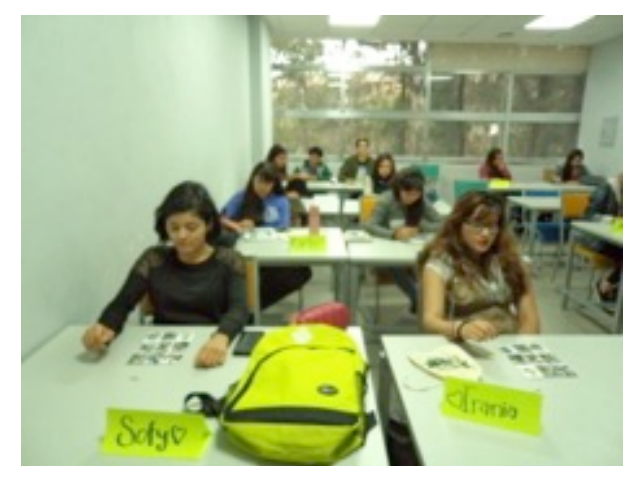

Técnicas hay muchas, pero lo principal es considerar lo que la misma cultura presenta posibilidades y elementos que pueden ayudar a desarrollar la cultura visual y sobre todo que pueden servir y aplicar como pretexto para motivar a nuestros alumnos.

Cabe resaltar que en el diseño la creatividad y la originalidad forman una bina que armoniosamente se conjugan para desarrollar productos de comunicación visual, logrado por la expresión y conjugación de elementos texto-imagen.

Al hablar de comunicación en el diseño, se establece una relación de expresión exterior, cuya manifestación se percibe por los resultados obtenidos del propio diseño. Nuestra mente es hábil y logra significar con expresiones visuales, donde entablará una conexión con el otro., de cierta 
manera será un placer sensible pues existe en un momento dado gozo y alegría por lo logrado.

No olvidar que la cultura visual se logra trabajando las formas y los colores, pero que en esta actividad es importante aclarar que solo se toma el concepto de la lotería, dejando por un lado la forma y el color representativo en la lotería mexicana. Quizá por el diseño de la actividad no está establecido como un requisito, pero podría considerase a futuro.

Pero al conjugar la gamificación con un aspecto de la cultura visual mexicana, se la logrado desarrollar una actividad lúdica de enseñanza-aprendizaje, dejando una experiencia en el alumno significativa, puesto que cada uno establece el mecanismo de selección y basado en la experiencia, donde el adapta la imagen al significado del personaje que le ha correspondido trabajar para el logro del armado de los cartones o cartas y poder compartir con los demás compañeros su imagen, una vez armado estos por cada uno de los estudiantes, se procedió a jugar. Logrando así un proceso de enseñanza y de recapitulación de conceptos basados en el proceso editorial como parte teórica del semestre, donde la imagen captada ha de permitirle al alumno recordar la acción que le corresponde, ya que hubo el momento de concer a cada uno de los personajes que se encuentran en el proceso editorial. 


\section{Referencias}

Alsina, P. Díaz, M. Giráldez, y A. Ibarretse, G.(2013). 10 ideas clave para el aprendizaje creativo. Barcelona: Editorial Graó.

Costa, J. (2003). Diseñar para los ojos. Bolivia: Joan Costa y grupo editorial Design.

Eggen, P. y Kauchak, D. (2009). Estragefia docentes (pp. 53-58). México. Fondo de Cultura Económico.

Marina, J. y Marina, E. (2013). El aprendizaje de la creatividad. Barcelona: Editorial Ariel.

Medina, R. A. y Domínguez, G.M. (2006). Didáctica. Formación Básica para profesionales de la educación. Revista Española de Pedagogía, LXIV, № 233, enero - abril, pp. 69-104.

Winner, E., T. Goldstein y S. Vincent-Lancrin (2014), ¿El arte por el arte? Resumen, OECD Publishing. Recuperado de https://www.oecd.org/education/ceri/ES_ARTS_overview_V5_print.pdf

Zapata, F.C (2010). El juego y sus raíces. Un acercamiento simbolico a la identidad cultural de un pueblo. Recuperado

de:

http://observatoriocultural.udgvirtual.udg.mx/repositorio/bitstream/handle/123456789/602/C LGC051.pdf?sequence $=1$ \&isAllowed $=y$ 